\title{
The futures of construction management research
}

Article

Accepted Version

Harty, C. and Leiringer, R. (2017) The futures of construction management research. Construction Management and Economics, 35 (7). pp. 392-403. ISSN 1466-433X doi: https://doi.org/10.1080/01446193.2017.1306089 Available at https://centaur.reading.ac.uk/70671/

It is advisable to refer to the publisher's version if you intend to cite from the work. See Guidance on citing.

To link to this article DOI: http://dx.doi.org/10.1080/01446193.2017.1306089

Publisher: Taylor \& Francis

All outputs in CentAUR are protected by Intellectual Property Rights law, including copyright law. Copyright and IPR is retained by the creators or other copyright holders. Terms and conditions for use of this material are defined in the End User Agreement.

\section{www.reading.ac.uk/centaur}

\section{CentAUR}

Central Archive at the University of Reading

Reading's research outputs online 


\title{
The Futures of Construction Management Research
}

\begin{abstract}
Construction management is an internationally recognised area of research with an established and growing community of academics. It has grown from largely 'research consultancy' activities to additionally attracting significant amounts of academic research funding and has, partially, moved away from its applied, engineering dominated origins to increasingly engage with, and contribute to, mainstream academic debates in business and management, economics and the social sciences. It has, as such, become an academic field in its own right. However, recent dynamics within both university institutions and national economies are changing the landscape of construction management research. A blurring of traditional university boundaries, reprioritisation of research funding and increasing emphasis on national and international rankings have led to increased pressure on individual academics and the community they constitute. Drawing on scenario development we ask what, in the face of a turbulent environment, might the futures of construction management research be? Four potential futures for construction management research are outlined, depicted as four potential scenarios: convergence, retrenchment, disappearance and hybridisation. These describe potential outcomes from the institutional dynamics currently at play. The intention is neither to predict the future, nor to prioritise one scenario over another, but to open a debate on the institutional pressures the field is facing, and what the outcomes might be.
\end{abstract}

Keywords: construction management, futures, institutional trends, academic fields 


\section{Introduction}

Since the 1970's, construction management (CM) has emerged as an internationally recognised area of research with a recognisable and growing community of academics. Over this period, construction management research (CMR) has grown from largely 'research consultancy' activities to additionally attracting comparatively large amounts of research funding, and has partially moved away from its applied, engineering dominated, origins to increasingly engage with, and contribute to, mainstream academic debates in business and management, economics, and the social sciences [note: $\mathrm{CM}$ is here positioned as related to, but distinctively separate from, construction technology. CMR constitutes management and organisational research in construction]. However, recent dynamics within both university institutions and national economies are now changing the landscape of construction management research. Noticeably, universities in general are in transition (Göransson and Brundenius, 2011). Increased competition for student recruitment has led to a growing emphasis on national and international rankings with associated pressures on individual academics to publish in pre-defined areas, and commercialise and 'spin out' research activities (Chan, 2012; Rauhvargers, 2013). Concomitantly, in many parts of the world the recent economic crisis has not only stunted growth of construction sectors, but also resulted in a reprioritisation of research funding.

In the face of this turbulent environment it is worth posing the question of what the futures of construction management research might be. This paper builds on Authors $(2007 ; 2008)$ in illuminating and unpicking emerging trends and how these can come to affect the CMR community at large. It follows on from the longstanding debates around the nature, purpose and future of academia that have been held within mainstream management circles (e.g. Pfeffer, 1993; Gulati, 2007; Learmouth et al., 2012), as well as more recent contributions in adjacent sub-fields such as: strategic management (e.g. Nag et al., 2007), supply chain management (e.g. Sanders et al., 2013), and most prominently project management (e.g. Horner Reich et al., 
2013; Söderlund and Bakker, 2014; Bresnen, 2016). The aim is to account for the potential effects of a number of emerging trends and contribute to the nascent discussion on the future directions of CMR in this journal (e.g. Bresnen, 2017; Koskela, 2017; Leiringer and Dainty, 2017).

Our starting point is a broad sketch of the origins and development of CMR. We note that traditional construction management researchers have increasingly become more focused on issues related to more mainstream management and organisation studies. Furthermore, there has been a steady influx of researchers from a variety of disciplinary backgrounds finding their home within the $\mathrm{CM}$ domain, as well as researchers from other disciplines showing an increased interest in construction in their studies of management and organisation (Schweber and Leiringer, 2012). We make the case that even if it is not always possible to provide clear boundaries around what is to be included in the term construction management, the necessary characteristics for it to be considered an academic field exist. Following on from this a framework is presented that allows for the dynamics affecting CMR to be examined at three different abstraction levels: network, institutional and external. The argument then turns to the many co-existing pressures that $\mathrm{CM}$ academics face and an attempt is made to position these against increasingly noticeable trends within and outside the university system. Drawing on principles taken from the intuitive logics school of scenario planning we develop four potential future scenarios for CMR: convergence, retrenchment, disappearance and hybridisation. The objective is not to draw strict conclusions or prioritise one scenario over another, but to begin an open debate on the heterogeneous and contradictory pressures being faced within CMR, some of their possible outcomes and the future of this comparatively young academic field. 


\section{Construction management research}

Although there are several examples of early chairs in building economics ( Bröchner, 2009), CMR has its home within the engineering sphere (Asforth, 2009). It has frequently been associated with the more technical disciplines (Langford, 2009), and has been dominated by the 'engineering paradigm' of knowledge creation; i.e. the application of scientific knowledge in an applied domain (Stokes, 1997; Becher and Trowler 2001) utilising positivist and quantitative approaches (Fellows and Liu, 1997). However, over time, the breadth and scope of what is commonly included in the term construction management has expanded. Long gone are the days when it was an extension of operations management in the construction context, even if there are still debates as to the extent of methodological variety within the field (cf. Dainty, 2008). CMR is today populated by individuals with vastly varying backgrounds who do not necessarily share the same ontological and epistemological perspectives regarding the methods they mobilise and the products that their work generates (Schweber, 2015). This has resulted in a broad and heterogeneous body of knowledge built upon findings from studies conducted through a plethora of approaches based on diverse, and competing, theoretical underpinnings (Dainty, 2007; Fernie and Leiringer, 2009). Hence, on the surface there is little that connects many of the $\mathrm{CM}$ academics in terms of background and beliefs on how research should be carried out. Yet, they do nonetheless coalesce to form recognisable organisations - e.g. research groups, divisions, departments, schools and faculties. On a bigger scale, rather than necessarily being united by a common understanding, $\mathrm{CM}$ academics are joined together by a system of social relations. They regularly interact through multiple activities such as: the refereeing process; co-authorship of books and conference and journal articles; visiting professorships; the external examination system; membership of various committees and professional bodies; national and international conferences and; numerous seminars, panels and events. Accordingly, it is possible to conceptualise CMR as an arena with particular co-evolved logics 
representative of the configuration, coherence, interests and formation of its members over time (cf. Oliver and Montgomery, 2008). Hence, while there might not be a clear cut definition of the term 'construction management', CMR can nonetheless be conceptualised as an academic field in its own right, with a relatively easily defined membership and set of social dynamics (cf. Whitley, 1984).

\section{Conceptualising the field - networks, institutions and the external environment}

For the purposes of this paper we find Whitley's (1984) definition of fields to be particularly useful. He defines an academic field as a social organisation of academics engaged in both the pursuit of novelty and the collective production of knowledge, revolving around a reputational system which confers recognition for contributing to that body of knowledge. Hence, in this definition the field is not dependent on any distinction between types of knowledge produced, such as pure versus applied, or methodological coherence. Instead, it is created by reputational and bureaucratic structures, and networks around academic activity.

Whitley identifies three broad sets of dynamics that affect the academic field. The first of these is centred on 'networks'. Field cohesion is formed through a diverse variety of strongly or weakly tied networks, without which the field will break up. The relative cohesion of field and the field-based elites who confer reputational recognition are, therefore, important determinants for whether the field is strongly bounded, or more loosely organised. However, too much coherence restricts the ability to contribute acceptable new knowledge. This is not to say that the type of knowledge and the way it is produced is not important. There is a tension between the uncertain outcomes of the pursuit of novelty through scholarship, and the production of knowledge which aligns with collectively accepted norms, approaches or concepts. Indeed, this could, arguably, lead to the adoption of research techniques, which match the academic network reputational criteria, over individual interests or relevance to the research problem. 
Irrespective, the conferring of recognition through networks of academic peers is a key feature of field membership.

With a few obvious exceptions (e.g. research institutes), the majority of research active academics are located within university (Higher Education) institutions, which play a significant part in the constitution and dynamics of the field. Thus, the structure and operation of the university adds a second set of 'institutional' dynamics alongside the network. These institutional dynamics partly support the reputational system, but also impose a level of bureaucratic control over the employed academics, in terms of imperatives around, for example: income generation or preferred funders, interdisciplinary initiatives, commodification of research outputs, or even development of new markets for undergraduate teaching. A clear goal for the institution is also the reduction of risk with associated attempts to make the pursuit of novelty more predictable and, therefore, manageable and repeatable. This is exercised through the ability to control resources and incentivise particular activities, but brings with it a tension between control and academic freedom to pursue new ideas as well as a potential conflict between the field and the institution.

Academics are subjected to reputational and regulatory pressures, such as research assessment exercises, publishing conventions and promotion boards. But the pressures are not only academic, whether reputational or bureaucratic. Research in an applied domain, such as construction management, requires external participants, i.e. individuals, organisations and sectors who see value in the work. Such actors have their own ideas about the function and contribution of the academic community spanning the spectrum from an interest in long term, theoretically informed research, to short term, problem solving with direct impact. This points towards a third set of dynamics influencing the academic field - the 'external' pressures of industry, government, funders and other consumers of research outputs. These may be more or less aligned with both network and institutional dynamics. University strategies around research 
income are, for example, continually redrawn to resonate with government policy or funding initiatives, and 'research friendly' high profile industrialists are prevalent in research settings. But these external dynamics are, nonetheless, recognisable as influences on the constitution, development and continuation of the field as a whole.

Combining network, institutional and external types of control, as outlined above, provides a basis for a tripartite framework of field level dynamics, which allows the teasing apart of a host of different factors, drivers and pressures in order to think about future developments. By distinguishing between research network, university institutional, and external / industry dynamics, the framework moves beyond the relevance versus rigour debate, which has been well rehearsed over the past few decades in management circles (cf. Hammersly, 2000; Pettigrew, 2001; Starkey and Madden, 2001). It does so by making a distinction between reputational and bureaucratic control, rather than characterising the dynamics of research as a tension between academia and industry. This is important as, whilst it is clear that for research to be relevant and academically sound it needs to be credible in both locations, the mechanisms through which credibility is endowed are not unproblematically aligned to each. The framework is, thus, useful as it allows for greater acknowledgement of how reputational recognition and credibility (Breslau, 1997) is gained. In short, the framework allows a more nuanced acknowledgement of academic and external pressures. In the following sections we give an account for how the three dynamics play out in CMR, and map out the emerging trends and the current pressures within the three sets of dynamics that affect recognition and credibility in the field. We do so in recognition that these different trends align and support each other, as well as contradict and cause tension. We concentrate on publishing and evaluation of research, the tension between research and teaching, and the forever evolving impact agenda. 


\section{Exploring the dynamics of the CMR Field}

\section{Publishing and Research Evaluation}

Within academia established reputational sources of credibility are underpinned by a disciplinary structuring of knowledge and peer review. Historically, academia has revolved around a number of more or less internally consistent and relatively homogenous social and organisational structures (Whitley, 1984; Breslau 1997). However, the balance between pursuit of novelty and new knowledge and regulatory institutional pressures is gradually changing. Most noticeably, reputational credibility is increasingly dependent on journal rankings and citation indicators. For universities, in general, citations and journal rankings are now increasingly used as an index of institutional quality and as a means to establish prestige (Bornmann et al. 2013; Rauhvargers, 2013). The 'value' and 'quality' of a publication is measured against the perceived quality of the journal it is published in, the number of citations it gets, and a variety of time related indexes (van Raan, 2005; Rauhvargers, 2013). It follows that, publications in high ranking outlets and citations accrued by academic units are significantly related to rankings of their academic quality (Judge et al., 2007). Even if there are alternatives, such as 'SCImago Journal Rank', the Thomson Reuters' (Web of Science) 'Journal Citation Reports', with all its flaws (see for example Macdonald and Kam (2010) for an extensive critique), has become a dominant measure and is recognised in most countries.

Several key institutional trends are shaped by (and reinforce) the above view of academic credibility. For example, evaluations of 'research excellence', in various guises, are becoming ever more common across the world (e.g. Australia, Hong Kong, Italy, Portugal and United Kingdom). In general, these are predominantly based on assessment of publications, and the results have a significant impact on the allocation of state funds. Publications, and in particular citations, are also significant factors in broader based University ranking exercises; e.g. 
counting for appr. $36 \%$ of the total score within the Times Higher Education rankings (THE, 2014). A further example is the emphasis and weight given to publications and citation indexes by major funding bodies, not least national research councils. This is evident in the assessment of research proposals, but is also prevalent in various national ratings of individual academics, e.g. the National System of Investigators of the Agencia Nacional de Investigación e Innovación in Uruguay (SNI, 2016) and the NRF Rating by National Science Foundation in South Africa (NRF, 2016).

All in all, the above described developments lead to mounting network and institutional pressures on individuals to publish. More specifically, it has led to the development of official and sometimes highly unofficial reward systems that incentivise (or coerce depending on the view taken) authors to publish in certain types of outlets. The end result is a university system where publications, citations and impact factors are intrinsically linked with the procedures of appointment, promotion, pay and external funding decisions. This is a development that is, arguably, rather more towards heavy handed bureaucratic control than flexibility to pursue novel ideas and new opportunities through research.

For established academic disciplines and mature fields the above depicted developments provide a rather consistent playing field. Even if some disciplines have proven to be more resilient against the increased use of metrics, there is a recognisable quality distinction between higher and lower rated journals in a particular domain, and there is critical mass around specific approaches and theoretical positions. This enables a more coherent, stable and over time cumulative peer network. In CM, however, the ideas of disciplinary structuring through reputation are not at all straightforward. To start, the diversity of epistemological and ontological positions of the field's academics and the variety in research topics and theoretical underpinnings characterises research outputs and, ultimately, hampers the accumulation of a homogenous knowledge base. Second, the development of narrower, specialist journals, such as 
those seen in organisational studies, have been difficult to sustain in CM. Indeed, development has, over the past decade, seemingly gone the opposite way with a proliferation of broad allencompassing CM journals with very little differentiation in terms of scope. The corollary is that the dense referential networks that characterise established academic disciplines are much less evident in CMR, as evidenced by the low number of journals that are included in the Web of Science.

It is, therefore, not clear how a CMR academic gains high institutional credibility while publishing within the CM field. It further follows that the way in which these current 'rules of the game' are evolving unavoidably puts the CMR unit as a whole at a disadvantage against many other departments and faculties. A logical response, which is increasingly finding traction, is for CM academics to attempt to publish in 'ranked' journals outside the field, and to participate in conferences in more mainstream organisational, management and engineering areas. This is, however, not necessarily straightforward as it can necessitate changes in content, methods and presentation. Indeed, it is the same dynamics of gaining reputation being played in a different set of networks. It also risks the coherence of the field-level CMR network as those who are successful start to engage with, and move into, other competing fields.

\section{Teaching and Practice}

Notwithstanding the above, it is important to stress that research is not the only way which field dynamics affect CMR academics. The competition for attracting students is fierce. The importance of publications in establishing university rankings has clearly grown, but teaching remains central to a university's success in this competition. This has brought with it other, rather inconsistent, institutional demands regarding the focus of research and dissemination of outputs. Academics are expected to respond to new and emerging problems and to engage with current non-academic priorities. At the same time, academic institutions are expected to provide 
a relatively stable platform of knowledge (i.e. text-book learning) in digestible chunks, which informs, and sometimes even constitutes, the activities, problems and contexts of 'construction' and 'construction management'. This brings tensions between training students to become effective practitioners and providing an academic education. This is not least apparent in the professional accreditation processes. There is now even evidence towards academic units in countries that do not subscribe to the professional system starting to look for professional accreditation for their courses as a means to remain competitive on the international scene. For example, in an interview, the Dean of the School of Architecture and the Built Environment, KTH Royal Institute of Technology in Stockholm describes seeking international accreditation for domestic courses as a way of attracting international students (Hult, 2010).

Somewhat paradoxically, it has long been argued that university teaching in general, and management education in particular, does not provide industry with individuals possessing the relevant skills to increase firms' competitive edge (e.g. Linder and Smith, 1992; Pfeffer and Fong, 2004). But it remains the case that the success of university institutions is, largely, governed by the attraction of students, which is, in no small way, derived from the employability of graduates with qualifications from specific schools or universities. Also, worth remembering here is the increased financial significance of the provision of self-funded courses as well as continuous professional development (CPD) and company-bespoke courses (at times at the scale of academies) offered and accredited by universities. This involves a greater convergence between external and institutional reputation.

\section{Research and external stakeholders; the impact agenda}

Examining the status of research outside of academia we find that it is more heterogeneous than within the academic reputational system. External credibility and recognition is conferred by multiple groups, including advisory panels, private and governmental research funders, industry 
spokespersons and practitioners etc. In business (broadly defined), credibility comes from the practical (and non-academic) implications of research, and from its utility as a resource for controlling, influencing or understanding business contexts. Thus, looking at academic outputs from an industry perspective it is clear that the effectiveness of the resultant outputs in actually impacting on industry and society is not deducible from citation indexes or journal rankings. Furthermore, it is indubitable that few in industry would ever worry about citations, or which journals academics choose to publish in. Much more important are the direct benefits that might accrue from the research outputs and the perceived competitive advantages that these might bring. In terms of framing research potential impact is good, but easily identified benefits are better. There is little doubt that industry prefers short term solutions ahead of potential for longterm impact, and that there is a link between external credibility and the ability to provide such solutions. Research closely focused on solving current industry problems and, hence, with supposedly high relevance, is also seemingly favoured from a policy and funding perspective (Fernie et al., 2006; Green, 2011). Here, recent trends towards increased emphasis on match funding by national research bodies can be argued to be further increasing industry influence on academic research. For instance, the UK's Innovate UK funding board requires industry led proposals with matched funding from private companies, with academic institutions posited as supporting partners.

In light of the above, it is not farfetched to argue that there is growing congruence between institutional bureaucratic pressure and external reputation. Research impact on industry and society is clearly an increasingly important measure for university ranking and income. But this risks moving further away from peer networks awarding reputation based on novelty. Furthermore, increasingly there are moves to physically bring academia and industry closer together and there are emerging trends towards blurring out the traditional university boundaries. This takes many forms, but is noticeable in: the provision of space for start-up 
companies on university campuses; the establishment of science parks on or near university grounds; and the co-location of commercial organisations and academic units. There is also an increasing trend towards industry facing education with universities moving beyond offering various forms of CPD courses and part-time degrees towards bespoke MSc courses with organisations guaranteeing a fixed number of students per year, and even the delivery of specially tailored 'academies' by one or several universities for public as well as private sector organisations. Examples of the latter include the public sector National Academy for Project Management (Neerlands Diep) and the private sector Shell Project Academy, in the Netherlands. Universities are also increasingly moving into areas such as spin-off commercialisation of research outputs and consultancy. Indeed, 'enterprise', commercial as well as social, has become a key strategic theme in many universities.

The corollary for the CMR field of the above described trends is that academics increasingly have to sell their ideas (and themselves) to a range of potential customers in competition with other players in turbulent and increasingly overlapping marketplaces. It is not quite so simple as offering distinctive qualities or 'unique selling points' of academic research - which traditionally has tended to be its scholarly rigour; its particular (non-business based) approach to understanding; and its commitment to long-term knowledge development. While this might represent a greater convergence between external and institutional reputation, it is still some distance from the network reputation system constituted by academic peers.

\section{Four future scenarios for the CMR community}

If the discussion above tells us anything, it is that construction management as a field of enquiry is dynamic, and currently facing a number of pressures which cannot simply be accounted for as academic versus industry priorities. In the past, we have described how individual academics respond to these pressures as 'playing the game' (cf. Authors, 2008). By 
this we do not mean practices such as writing- and citation 'clubs', and over-use of data sets across multiple publications. Nor do we mean chasing citations through social media marketing. Our argument has been that CM researchers, in general, are very good at working with industry and getting research funding. Indeed, many researchers and research institutions pride themselves on developing and maintaining long-term relations with both research funders and industry partners. We have further argued that $\mathrm{CM}$ academics are more or less sensitive to the larger contexts in which sectors, businesses and other institutions, such as universities and research councils, operate, and that most try to take measures to position their research accordingly. Thus, our view has been that $\mathrm{CM}$ academics have adapted to existing and emerging pressures by playing multiple games across different stakeholder arenas. It is through concerted efforts to play these multiple games that ideas and outputs are constituted and transformed as they go through processes of funding, researching and publishing.

This argument has, however, revolved around the plight of the individual academic and it is clear that there are some potential structural risks in this. Swinging too far towards impact and relevance can come at the price of drifting away from the epistemic terrains of academic research (cf. Elzinga, 1985). Too far the other way potentially removes CM scholars from both their empirical context and their market for graduates. CMR is a relatively new field, but neither of these options feel sustainable in the long term. So, instead, we now begin to tentatively extrapolate some of these dynamics - the pressures around publishing and funding, the increasing external emphasis on 'impact' or relevance, and the shifting landscapes of construction sectors - from a CM field perspective, rather than at the individual level.

Our approach draws on the main principles from the intuitive logics school of scenario development (Amer et al., 2013). This is a highly subjective and qualitative approach, which allows us to derive a qualitative set of plausible scenarios together with their implications in a narrative form (ibid.).We would stress here that these scenarios are not predictions, and we are 
not trying to propose any scenario over another, or give providence to any particular reputational control mechanism. Nor are we trying to privilege any set of activities over another. Furthermore, we are not claiming that the sorts of activities variously described below are novel or our own invention; they are, in one form or another and to varying degrees, happening already (in CMR as well as in other domain based research fields). But as tools for thinking about the continual development of CMR these scenarios demonstrate, if nothing else, the range of potential futures ahead. So, based on our mapping of trends across the three abstraction levels and taking into consideration both reputational and bureaucratic controls, we suggest four potential narratives of the future below; convergence, retrenchment, disappearance and hybridisation.

\section{Convergence}

This scenario considers the harmonisation of the body of knowledge and sets of research problems around which CMR might be oriented. The development of disciplines can be roughly characterised as moving towards increasing specialisation and fragmentation, for instance into various sub-disciplines, or as converging on a set of specific problems, epistemological positions and empirical spaces (cf. Abott, 2001, Pfeffer, 1993). Indeed, Kuhn's model of 'normal science' describes the slow accumulation of new knowledge around established and consensual theoretical positions - paradigmatic revolutions are both few and far between. Thus, in this scenario there is a consensus on the core topics and problems that CMR is concerned with, as well as on the methodological approaches and theoretical positions to address them. There is also a set of distinct construction management journals in which research findings are disseminated; and consensus will have materialised around a series of 'classics' that set the paradigm for the subject, and for a highly coherent field. 
The consistent calls for the CM community to become more cumulative in its knowledge production, and to stop reinventing long-standing problems and repeating existing research studies, could be one driver to bring about this scenario. Another driver might be the institutional pressures to position research intensive CM schools, departments and divisions as having a distinct and clear identity within the university, in order to compete for internal resources and support. The need to improve citation rates is a further potential driver - a shift towards a narrower and more incremental agenda would lead to more consistent and regular citation of previous related work. In terms of industry relevance, the continual search for improvement would presumably find favour across large swathes of any construction sector. However, this needs to be approached with caution. Existing, similar work may seem alluring and straightforward in terms of application, but the actual uptake of academically derived redesign of construction firms or processes has been limited.

In research terms, this scenario implies shared approaches and languages to enable gradual accumulation and incremental additions to an accepted knowledge base. As a field, CM becomes more cohesive, homogeneous and clearly differentiated from related sub-disciplines (such as social science management and organisation studies). In terms of funding, the research agenda, certainly, would reflect an emphasis on impact, and a coherent voice might have more persuasive power in terms of expressing the need for research funding. CM journals would become similarly more coherent and cohesive, with the potential to compete on reputation with more 'mainstream' journals on the basis of increased citation rates and various impact factors. A strongly focused field would lead to journals that reflect and represent this focus. Where exactly the main focus would be put is, however, by no means evident. But there has always been an extensive amount of research around improvement and efficiency issues within construction management, such as learning across projects, critical success factors for projects or firms, productivity (at organisational and sectorial levels) and so on, which, implicitly or 
otherwise, generally adopts a positivistic and instrumental / rational perspective. This application of, broadly, operations management oriented approaches could come to define a coherent research agenda for the CMR field. However, this would narrow the opportunities for diversity and, in a community sense, risks the ostracising of those few voices which speak outside of the accepted majority. Indeed, one of the key characteristics of CMR is its diversity, and the way it (sometimes well, sometimes less well) draws on a whole range of supporting disciplines.

\section{Retrenchment}

The relatively short history of CMR can be characterised as moving from an initial focus on supporting industry, through consultancy, provision of specialist expertise and response to emerging sectoral or policy shifts, to one where the field looks outside of itself and engages with theories, methodological approaches and debates outside of construction management whether within the social sciences, organisational studies or elsewhere. Retrenchment describes a scenario where the $\mathrm{CM}$ field withdraws from the pursuit of 'pure' funding, academically oriented publication and research drawing on established disciplines. As such, it is something like a return to the roots for the field. It moves away from 'academic' funding and research programmes towards a core of delivery of industry-approved teaching and shorter-term consultancy activities for the construction sector. Strong and successful undergraduate and post-graduate recruitment and education delivery keeps construction management's identity and positioning within universities as both an income generator and a provider of specialist education. Closeness to industry remains and, if anything, the gap between university and practice is reduced. Consultancy and the provision of specialist expertise to the industry for more short-term oriented problems become the main non-teaching activities for CM academics. Journals become much more practitioner-oriented, reporting case studies or developments 
within the sector, with less emphasis on drawing on or standing alongside academic perspectives and theories from other disciplines.

There are several drivers that might lead to this scenario. To start, it is a fact that construction management research is not highly cited outside of $\mathrm{CM}$ journals and, accordingly, not seen externally as contributing to debates in more established disciplines. Furthermore, publishing in high quality journals outside of $\mathrm{CM}$ is a real challenge, which demands a shift in research designs as well as in the presentation of academic research. Indeed, the reputation-building activities, which are part and parcel of the academic profession (as well as of career advancement), are time consuming as it is, let alone taking on other disciplines. The resulting lack of publications in high impact journals, and citations thereof, is increasingly likely to impact on funding possibilities. The competition for funding is increasing, and the lack of reputation, profile and disciplinary background can act as a barrier to $\mathrm{CM}$ academics accessing funding sources more usually associated with either social science or hard-engineering / science. Developments in national and international university rankings, with citations becoming a key indicator, also serve to undermine CMR's standing within the university institution. However, the community would always be required to teach and train the emerging generations of construction professions and provide specific post-graduate training. This requires an understanding of the industry that the graduates will enter. It also requires the continual development of sector specific knowledge and capabilities as the sector itself evolves - making external reputation important. A move towards more industry-centred, practically relevant teaching would, thus, also lead to reprioritising research efforts in order to satisfy busy, and experienced, professionals.

In many ways this looks like a healthy scenario for the CMR field, with a combination of a strong institutional position and closeness (and hence relevance) to industry. However, this potentially spells the end of the nascent development of CM as an academic discipline with its 
own body of knowledge, set of approaches and character. It could also lead to a potentially tenuous position for academic units in institutions which consider themselves more 'research active'. Given the fact that national league tables tend to privilege these in the rankings, it might eventually damage the academic reputation of $\mathrm{CM}$ education programmes within the sector. Individuals might also find themselves forced to change job titles as to "fly under the radar' in research assessment and ranking exercises. A further risk with being overly close to industry, and responsive to industry demands, is continuing to follow whatever fads, fashions or policy improvement agendas that are rolled out (cf. Green, 1998). Chasing relevance would remove a small but important function of the field; that of being a critical voice of both policy and the activities of the sector, and an advocate of those who run counter to the instrumental rhetoric of 'business'.

\section{Disappearance}

It is not far-fetched to describe CMR as having occupied a rather uncertain space in academia, juggling industry relevance while competing in a crowded academic space of two to four year publication processes, large data sets, disciplinary conventions and, not least, a diverse set of similar (but perhaps more established) research fields. Competing in the various established disciplinary spaces is a significant challenge, but in this scenario, as a field (rather than individually), CMR is successful. Success in this sense means answering to bureaucratic and network controls by: publishing, and being cited, in mainstream social science and organisation journals, rather than construction management specialist journals; securing the majority of the research income from social science funding bodies; and establishing CMR as a community of academics, which makes substantive contributions to debates about individuals, organisations, and society. In other words, it means construction management dissipating as a distinct entity, with academics and research moving from more or less dedicated construction management units into business schools, social science and engineering faculties/departments. Mainstream 
journal outlets, general funding and broad academic quality become the benchmarks for success.

This scenario is driven by, on the one hand, the pressure to chase funding opportunities outside the CM domain and, on the other, the chase for citations and publishing in highly rated academic journals - with all the necessary changes in research designs and views on knowledge accumulation that it entails. It suggests a disconnect between research and teaching, with the latter's focus on providing transferable skills and sector specific practical knowledge. It also represents a risk to the specific industry connectivity the CMR community currently enjoys. In other words, academic credibility as constituted by peers together with bureaucratic pressures has taken the upper hand over external pressures. Research, then, becomes longer term and further removed from the messy everyday realities of construction, and much more oriented to a different academic community. Indeed, the full implication is that the CMR field merges with, or is subsumed within, more established academic disciplines. A first step could be through joining university cross-departmental research institutes. In research output terms, specialist construction management journals also disappear as academics relocate to non-CM units and submit to non-CM publications. Ultimately, construction management as an area with a distinct identity and existence inside universities disappears. The community becomes a diaspora across a range of different disciplines and institutional departments. Construction becomes just an empirical domain, the subject of academic scrutiny from organisation scholars and social scientists. CMR is no longer unique, although it does make a contribution to knowledge within these disciplines.

This raises some fundamental issues regarding the CMR field. First, what would happen to the education programmes? We already hear of large consultant and contracting organisations who no longer want to recruit construction management graduates; rather they want to recruit civil engineers, architects or scientists, and then train them in management internally. At the same 
time, professional accreditation is increasingly prioritized. Construction management degrees are dependent on demand for graduates, if this demand declines, so too does student recruitment. Second, industry impact becomes a secondary concern to more introspective (and rigorous) academic research. The connectivity with the sector will, inevitably, be weakened through this; and although it removes the problem of becoming handmaidens to industry, the relatively unproblematic access currently enjoyed by many $\mathrm{CM}$ academics will become more of a challenge, and long term relationships difficult to establish and maintain. These two issues are intimately linked. A large part of the demand for graduates stems from the sector recognising that the field knows something about construction management, that it has a profile as a community contributing to the sector, and that it provides knowledge that the sector lacks. If this level of relevance and engagement is taken away, CMR's reputation in industry could diminish and the demand decrease further.

\section{Hybridisation}

Following long standing discussions regarding knowledge production in general (e.g. Gibbons et al., 1994) and in management research in particular (e.g. Huff and Huff, 2001; Bresnen and Burell, 2013) there have been a number of discussions in recent years within construction management about the notion of co-production (e.g. Authors, 2008; Green et al., 2009; Stokes and Dainty, 2010). This is defined as the joint development of both research agendas and questions, and new knowledge which comes from it. Hybridization might be one way to describe the synthesis of the problems of relevance and rigour. Rather than take one over the other, or, indeed, try to do both simultaneously, research becomes an integrated process which clears the double hurdles (cf. Pettigrew, 1997; Markides, 2007). In this scenario CMR retains academic rigour, demonstrated through both the strength of specialist construction management journals and the community's presence in mainstream social science and management fields, and the field demonstrates the academic and impact reputation necessary to maintain healthy 
streams of funding. Cross citation between construction management and other areas leads to the rise of higher impact-factor $\mathrm{CM}$ publications, and the positioning of construction management within the agendas of business schools and similar. Hybridisation, as such, is a scenario where CMR retains its distinctiveness, continues to respond and be close to industry issues and, at the same time, is able to attract academic funding and contribute to mainstream knowledge generation.

What is significant here is that this scenario is not the same thing as combining all the 'good bits' of what the CM community already does. Instead, pushing the scenario further, it implies new ways of developing and conducting research, of producing new knowledge and achieving impact and quality. Future research agendas will not be developed independently or a priori, but emerge from the interaction between the industry and the $\mathrm{CM}$ community. Hence, academics will not be responding to specific problems, or policy and organisational agendas around efficiency, productivity, use of technology or whatever. Instead, they will be developing new questions, new foci and new approaches to enable responsiveness, continual feedback between participants, and the ability to flex with emerging challenges and interests. This requires not only a shift in the practices of the field, but also a shift in: funding and the structure and content of research proposals; a change in how journal articles are structured; and, not least importantly, in the expectations and practices of the industry.

Such a significant change in practice also implies a significant change in the institutional accoutrements around them. It would necessitate a rethink of reputational recognition and enforce the development of new bureaucratic controls. Hence, this model of hybridization is hardly a good fit with the contours of existing CM units. Nor is it a good fit with existing social science or business schools. The nearest we possibly get to this scenario are university hospitals with a strong connection between research, teaching and practice. They, however, have the advantage of the well-established methodical approaches, and the cohesive, incremental 
knowledge production described in the convergence scenario. Admittedly, there are, as previously mentioned, tendencies for universities and industry to co-locate and physically come closer together. But can we imagine the corollary university contracting organisation or estates department, i.e. a hybrid academic department with academics and practitioners moving in and out, with activities of research, teaching and consultancy being indistinguishable from one another? This would mean a very different institutional business model for CM units. New models of funding will be needed, where a mix of government, sectoral and individual firm resources are combined. This implies quite a radical change; not only in allocation such as match-funded and industry-led research, but also in the ways funding achievements are recognised and rewarded in terms of career progression, resourcing and so on. A new model of research output is also implied outside of demonstrating a particular version of academic rigour. We are, effectively, producing a new type of knowledge that is neither academic nor practical. Hence, what at first appears a persuasive and sensible third way around the impact versus quality (relevance vs. rigour) debate in fact becomes the most ambitious scenario, and the least consistent with current trends.

\section{Discussion and concluding remarks}

While national and international contexts differ it is clear that CM academics, around the world, find themselves facing numerous challenges and inconsistent demands. Industry is often characterised as wanting easy, directly applicable solutions. Research funders want industryengaged, problem-solving research which demonstrates external non-academic impact on the one hand and publications in quality journals on the other; and their priorities and funding systems are forever changing in attempts to resonate with industry and government. Universities as employers, place pressure on researchers in the form of: winning funding; the quality dissemination of corpus knowledge through teaching; and publication of cutting edge research that both addresses industry problems and maintains and enhances the academic 
reputation of the institution. Established fields are pressured by university re-organisation; the abandonment of faculties, the re-organisation around interdisciplinary themes. It is clear that institutional pressures within the university system are increasing the importance of bringing in research funding and publishing in high impact journals. Concomitantly, the importance of abiding to external pressures, not least through closeness to industry, is at an all-time high as funding bodies increasingly look for co- or match funding from industry, and push for noticeable impact on business and society. A formidable hurdle for CMR, and arguably most other domain focused research, is that of achieving a closer integration with the wider base disciplines of the social sciences whilst, at the same time, retaining the field characteristic skills of high contextual knowledge and the ability to interact with industry (cf. Bresnen, 2017). In terms of raising reputational credibility in the academic arena increasing or expanding the domain of inquiry, such as going from project management to management of projects, or changing 'the label on the jar', e.g. rebranding from CM to 'Built Environment', might add to the perceived relevance in certain arenas. But it also dilutes the field in terms of shared logics, whether social or intellectual, and does not address the issue of publishing in any way. Conversely, a case can be made for that some of the nested fields within CMR, such as for example Lean Construction, are in a stronger position here as they arguably have a stronger methodological coherence. However, such nested fields might well not be big enough to survive on their own.

One solution might be to think of CMR as having a certain amount of 'interpretive flexibility' (cf. Bijker 1992) to allow it to be shaped or mutated in different ways according to its intended audiences. However, beneath this flexibility must lie core research activities representing the real and autonomous interests of academics. Questions, therefore, arise of precisely how much flexibility the 'core' research inherently has to have and to what extent the shaping of research ideas can be separated from the research process itself. And how would we avoid the problem 
that in attempting to satisfy multiple audiences, the research itself becomes somewhat diluted or stretched, and thereby loses or changes its focus - Elzinga's (1985) 'epistemic drift'? As the priorities of academic institutions shift in responding to new external pressures, for instance demands from government to engage more with industry or to demonstrate the non-academic relevance of research, so too do their research agendas and research processes.

Here we have tried to map out existing and emerging trends on a research network, university institutional, and external / industry dynamics level. Our approach to scenario planning does not provide any scenario that is likelier than the others. Instead, this paper is about raising questions and has been written from a self-consciously confrontational perspective. The aim has been to illuminate the structures that govern the CM academic field and explore the potential impacts thereof. Given the nature of the exercise we are certain that there are trends that we have missed and that we might well have up- or down played the importance of some of those that we have reported on. Furthermore, we are sensitive to the fact that they will play out differently across countries and regions, even if one of the fundamental attributes of the CMR field is its international peer network. What we have done is to take these trends and explored what would happen if they appear in different configurations and with different degrees of importance given to them by the CMR field.

We have refrained from getting into a discussion about what is right and what is wrong; or what is good and what is bad. Our contribution, such as it is, is moving beyond a bifurcated debate between industry relevance and academic rigour, replacing it with a more finely grained framework which accounts for the synergies and tensions between a range of institutional, network and external dynamics impacting on academic activity. But if we do claim to make a strong argument here, it is that the CMR community as a field, in the light of current trends, is not capable of continuing to play multiple games, and that whatever the alternatives may be, the 
field is in a crucial period of transition. Our hope is that this stimulates debate and, hence, contributes to the development of the field.

\section{References}

Abbott, A. (2001) Chaos of Disciplines. University of Chicago Press, Chicago.

Amer, M., Daim, T.U. and Jetter, A. (2013) A review of scenario planning. Futures, 46(1), 23 40.

Ashworth, A. (2009) Developments in construction education in the UK, in Langford, D. and Hughes, W. (Eds.) Building a Discipline: The story of Construction Management. Association of Researchers in Construction Management, Reading UK

Authors 2007; 2008

Becher, T. and Trowler, P. R. (2001) Academic Tribes and Territories: Intellectual enquiry and the culture of disciplines ( $2^{\text {nd }}$ edition). Society for Research into Higher Education and Open University Press. Buckingham, UK

Bijker, W. (1992) The social construction of fluorescent lighting, or how an artifact was invented in its diffusion stage. In Bijker, W. and Law, J. (eds) Shaping Technology / Building Society Studies in Sociotechnical Change. Cambridge, MA.

Bornmann, L., Mutz, R., and Daniel, H-D. (2013) Multilevel-Statistical reformulation of citation-based university rankings: the Leiden ranking 2011/2012. Journal of the American Society of Information Science and Technology, 64(8), 1649-1658.

Breslau, D. (1997) Contract shop epistemology: Credibility and problem construction in applied social science. Social Studies of Science, 27, 363-394. 
Bresnen, M. (2016) Institutional development, divergence and change in the discipline of project management. International Journal of Project Management, 34(2), 328-338.

Bresnen, M. (2017) Being careful what we wish for? Challenges and opportunities afforded through engagement with business and management research. Construction Management and Economics, 35(1-2), 24-34.

Bresnen, M. and Burell, G. (2013) Journals a` la mode? Twenty years of living alongside Mode 2 and the new production of knowledge. Organisation, 20(1), 25-37.

Bröchner, J. (2009) Sweden. In D. Langford and W. Hughes (eds) Building a Discipline - the story of construction management. Association of Researchers in Construction Management, Reading.

Chan, S-J. (2012) Enhancing global competitiveness: university ranking movement in Asia. Evaluation in Higher Education, 6(1), 15-36.

Dainty, A. (2007) A review and critique of construction management research methods. Proceedings Construction Management and Economics 25th Anniversary Conference. Reading, UK, July 16-18.

Dainty, A.R.J. (2008) Methodological pluralism in construction management research. In A. Knight and L. Ruddock (eds) Advanced research methods in the built environment. Wiley, Oxford. pp.1-13

Elzinga, A. (1985) Research bureaucracy and the drift of epistemic criteria. In B. Wittrock and A. Elzinga (eds) The University Research System: The public Policies of the Home of Scientists. Almqvist and Wiksell International, Stockholm. 
Fellows, R. and Liu, A. 1997. Research Methods for Construction. Blackwell Science, Oxford, UK.

Fernie, S., Leiringer, R. and Thorpe, T. (2006) Rethinking change in construction: a critical perspective. Building Research and Information, 34(2), 91-103.

Fernie, S. and Leiringer, R. (2009) The construction management field: a bit of a dig. In proceedings of $5^{\text {th }}$ Nordic Conference on Construction Economics and Organisation, vol.1, Reykjavik, Iceland, June 10-12. pp.110-120.

Gibbons, M., Limoges, C., Nowotny, H., Schwartzmann, S., Scott, P. and Trow, M. (1994) The New Production of Knowledge: The Dynamics of Science and Research in Contemporary Society. London: Sage.

Green, S. (1998) The technocratic totalitarianism of construction process improvement: a critical perspective. Engineering, Construction and Architectural Management, 5(4). pp. 376386.

Green, S.D., Kao, C. and Larsen, G.D. (2010) Contextualist research: Iterating between methods while following an empirically grounded approach. Journal of Construction Management and Engineering, 136(1), 117-126.

Green, S. D. (2011) Making sense of construction improvement. Wiley-Blackwell, Oxford.

Gulati, R. (2007) Tent poles, tribalism, and boundary spanning: the rigour-relevance debate in management research. Academy of Management Journal, 50(4), 775-782. 
Göransson, B. and Brundenius, C. (eds) (2011). Universities in Transition: The Changing Role and Challenges for Academic Institutions. International Development Research Centre. Springer, Singapore.

Hammersley, M. (2000) Varieties of social research: a typology. International Journal of Social Research Methodology, 3(3), 221-229.

Horner Reich, B., Liu, L., Sauer, C., Bannerman, P., Cicmil, S., Cooke-Davies, T., Gemino, A., Hobbs, B., Maylor, H., Messikomer, C., Pasian, B., Semeniuk, M., and Thomas, J. (2013) Developing better theory about project organizations. International Journal of Project Management, 31(7), 938-942.

Huff, A.S. and Huff, J.O. (2001) Re-focusing the Business School Agenda. British Journal of Management. 12(S1), S49-S54.

Hult, M. (2010) Vassare profil och mer internationellt samarbete [Sharper profile and more international collaboration] Available at http://www.kth.se/abe/omskolan/organisation/skolledning/stellanintervju-1.68471 [accessed 2014-06-27],

Judge, T. A., Cable, D. M., Colbert, A. E. and Rynes, S. L. (2007) What Causes a Management Article to be Cited-Article, Author, or Journal? The Academy of Management Journal, 50(3), 491-506.

Koskela, L. (2017) Why is management research irrelevant?, Construction Management and Economics. 35(1-2), 4-23.

Langford, D. (2009) Early foundations of the discipline: the Post WWII Years. In Langford, D. and Hughes, W. (Eds.) Building a Discipline: The story of Construction Management. Association of Researchers in Construction Management, Reading UK 
Leiringer, R. and Dainty, A. (2017) Construction Management and Economics: New Directions. Construction Management and Economics, 35 (1-2), 1-3.

Linder, J.C. and Smith, H.J. (1992) The complex case of management education. Harvard Business Review (Sept-Oct), 16-33.

Macdonald, S. And Kam, J. (2010) Counting footnotes: citability in management studies. Scandinavian Journal of Management, 26(2), 189-203.

Markides, C. (2007) In search of ambidextrous professors. Academy of Management Journal, 50(4), 762-768.

Nag, R., Hambrick, D.C., and Chen. M-J. (2007) What is strategic management, really? Inductive derivation of a consensus definition of the field. Strategic Management Journal, 28(9), 935-955.

NRF (2016). NRF Rating. National Research Foundation, South Africa. Available at: http://www.nrf.ac.za/rating [Accessed on: 2016-11-17).

Oliver, A.L. and Montgomery, K. (2008) Using field-configuring events for sense-making: A cognitive network approach. Journal of Management Studies, 45(6), 1147-1167.

Pettigrew, A. (1997) The Double Hurdles for Management Research. In: T. Clarke (ed.) Advancement in Organisational Behaviour: Essays in honour of Derek S. Pugh. Dartmouth Press, London. pp. 277-296.

Pettigrew, A. (2001) Management research after modernism. British Journal of Management, $12,61-70$. 
Pfeffer, J. (1993) Barriers to the advance of organizational science: paradigm development as a dependent variable. Academy of Management Review, 18, 599-620.

Pfeffer, J. and Fong, C.T. (2004) The business school 'business': Some lessons from the US experience. Journal of Management Studies, 41(8), 1501-1520.

Rauhvargers, A. (2013) Global university rankings and their impact: Report II. EUA Report on Rankings 2013. European University Association asbl, Brussels.

Sanders, N.R., Zacharia, Z.G. and Fugate, B.S. (2013) The Interdisciplinary Future of Supply Chain Management Research. Decision Sciences, 44(3), 413-429.

Schweber, L. (2015) Putting theory to work: the use of theory in construction research, Construction Management and Economics, 33(10), 840-860

Schweber, L. and Leiringer, R. (2012) Beyond the technical: a snapshot of energy and buildings research. Building Research and Information, 40(4), 481-492.

(SNI, 2016) Sistema Nacional de Investigadores. Agencia Nacional de Investigación e Innovación. Available at: http://sni.org.uy [Accessed on 2016-11-17]

Starkey, K. and Madan, P. (2001) Bridging the Relevance Gap: Aligning Stakeholders in the Future of Management Research. British Journal of Management, 12(S1), S26- 40.

Stokes, C. and Dainty, A. (2011) Knowledge co-production in construction management research In: Egbu, C. and Lou, E.C.W. (Eds.) Proceedings 27th Annual ARCOM Conference, 57 September 2011, Bristol, UK, Association of Researchers in Construction Management, pp. $117-126$. 
Stokes, D. (1997) Pasteur's Quadrant Basic Science and Technological Innovation. Brookings Institution Press, Washington D.C.

Söderlund, J. and Bakker, R.M. (2014) The case for good reviewing. International Journal of Project Management, 32(1), 1-6.

THE (2014). World University Rankings 2013-2014 methodology. Times Higher Eductaion. Available at: http://www.timeshighereducation.co.uk/world-university-rankings/2013-14/worldranking/methodology [accessed on 2014-05-27]

van Raan, A.F.J. (2005). Fatal attraction: conceptual and methodological problems in the ranking of universities by bibliometric methods. Scientometrics, 62(1), 133-143.

Whitley, R. (1984). The Intellectual and Social Organization of the Sciences. Oxford, Clarendon Press.

\section{ENDNOTE}

1. Thomson Reuters sold the Web of Science in July 2016. 